NBER WORKING PAPER SERIES

\title{
WILDERNESS CONSERVATION AND THE REACH OF THE STATE: EVIDENCE FROM NATIONAL BORDERS IN THE AMAZON
}

\author{
Robin Burgess \\ Francisco J.M. Costa \\ Benjamin A. Olken \\ Working Paper 24861 \\ http://www.nber.org/papers/w24861 \\ NATIONAL BUREAU OF ECONOMIC RESEARCH \\ 1050 Massachusetts Avenue \\ Cambridge, MA 02138 \\ July 2018
}

We would like to thank João Amaro, Nick Cerkez, Gabriel Mesquita and Christiane Szerman for excellent research assistance, and Jonathan Colmer, Dave Donaldson, Thiemo Fetszer, Michael Greenstone, Kelsey Jack, Seema Jayachandran, Mushfiq Mobarak, Imran Rasul, Dimitri Szerman, Matthew Turner and Tom Vogl for helpful comments. We also thank participants at LSE Conference on Environmental and Developmental Economics, NBER EEE Program Meeting, RIDGE POL Forum, and Economics of Low-Carbon Markets Conference. Burgess gratefully acknowledges financial support from European Research Council Grant 743278 "Man and Nature in Developing Countries" and Costa from Rede de Pesquisa Aplicada FGV. The views expressed herein are those of the authors and do not necessarily reflect the views of the National Bureau of Economic Research.

NBER working papers are circulated for discussion and comment purposes. They have not been peer-reviewed or been subject to the review by the NBER Board of Directors that accompanies official NBER publications.

(C) 2018 by Robin Burgess, Francisco J.M. Costa, and Benjamin A. Olken. All rights reserved. Short sections of text, not to exceed two paragraphs, may be quoted without explicit permission provided that full credit, including $(\odot$ notice, is given to the source. 
Wilderness Conservation and the Reach of the State: Evidence from National Borders in the Amazon

Robin Burgess, Francisco J.M. Costa, and Benjamin A. Olken

NBER Working Paper No. 24861

July 2018

JEL No. O13,Q23

\begin{abstract}
Preserving wilderness ecosystems in developing countries is challenging because their remote location places them far from state control. We investigate this using $30 \times 30$ meter satellite data to determine how Amazonian deforestation changes discretely at the Brazilian international border. In 2000, Brazilian pixels were 30 percent more likely to be deforested, and between 2001 and 2005 annual Brazilian deforestation was more than 3 times the rate observed across the border. In 2006, just after Brazil introduces policies to reduce illegal deforestation, these differences disappear. These results demonstrate the power of the state to affect whether wilderness ecosystems are conserved or exploited.

Robin Burgess

Department of Economics, 32L.3.03

London School of Economics

Houghton Street London WC2A 2AE

United Kingdom

r.burgess@1se.ac.uk

Francisco J.M. Costa

Getulio Vargas Foundation (FGV/EPGE) Praia

de Botafogo, 190 / 1100

Rio de Janeiro, RJ 22250-900

Brazil

francisco.costa@fgv.br

Benjamin A. Olken

Department of Economics, E52-542

MIT

77 Massachusetts Avenue

Cambridge, MA 02139

and NBER

bolken@mit.edu
\end{abstract}

A data appendix is available at http://www.nber.org/data-appendix/w24861 


\section{Introduction}

A central challenge in global conservation is that the ecosystems to be preserved are, by their very nature, extremely remote. In many developing country contexts, governments can project some authority in national or regional capital cities, but in frontier areas, their authority becomes much weaker (Herbst, 2000; Michalopoulos and Papaioannou, 2014). This, in turn, may open up opportunities for illegal extraction. Because wilderness ecosystems, which represent about 20 percent of the world's land area (Allan et al., 2017), are by definition in the hinterlands, it is an open question whether the state can have effective reach so far from the bastions of state power. Despite substantial de jure rules that restrict development and promote conservation, states may have little room to affect de facto what happens in these outlying locations.

This paper explores the degree to which the state can exert regulatory control over these remote wilderness areas by examining whether there are discrete changes in deforestation at national borders. Because political and hence policy jurisdictions stop at the national border - but satellite data on conservation outcomes can be measured uniformly across the geography - by analyzing satellite data on deforestation at the international border we can examine the effect of national policies in these remote locations.

We focus on one of the most important global wilderness ecosystems - the Amazon rainforest. Covering more than 2 million square miles - about the size of the contiguous United States west of the Mississippi River - the Amazon plays a crucial role in the global carbon cycle and hosts an astounding amount of biological diversity. Its immense size implies that the rate at which it is deforested will affect the pace of global warming (IPBES, 2018). Hence understanding whether conservation efforts by Amazonian nation states are effective is an issue of international importance. Indeed if these national policies have no de facto bite then this renders meaningless both national and international accords to slow Amazonian deforestation.

To study the impact of national policy in the Amazon, we use a new annual 30 meter resolution Landsat 7 data set which allows us to monitor deforestation in a consistent manner over time and space from 2000 to 2014 (Hansen et al., 2013). The high resolution allows us to zoom in close to the border - our preferred specification uses a bandwidth of only $17 \mathrm{~km}$ on either side of the national border - to identify precise effects. We show that areas on both sides of the border look similar in most important geographic respects, such as slope and distances to urban areas, water, and roads. While our focus is on results analyzing the entire $12,800 \mathrm{~km}$ Brazilian border in the Amazon, we find similar results restricting attention to "artificial borders", i.e. typically straight lines drawn in unknown territory by former colonizers and which do not correspond to any preexisting natural or institutional border (Alesina et al., 2011). For these borders, there is no geographic 
feature at the border - and indeed, usually not even so much as a fence. ${ }^{1}$

We investigate the role of national regulation of deforestation by running spatial regression discontinuity designs, using as running variable the distance to the Brazilian national border. This paper therefore fits within a rich literature using borders to look at policy effects. ${ }^{2}$ Before proceeding to empirical estimation, we present a brief theoretical model that clarifies precisely what this type of estimation does, and does not, recover. This makes it clear that changes in national environmental regulations can both have a direct effect by changing the returns to illegal deforestation (and hence the propensity to engage in it) but also an indirect effect by changing the investment behavior of potential users of forested land (including their location choice). The model makes it clear that for forestry where (i) the share of capital in production is low, (ii) local supply of capital is likely elastic and (iii) the key factor of production (land) is fixed in space, the regression discontinuity is likely to recover the policy impact, and the direct effects are likely to dominate. This is in contrast to other sectors like capital intensive manufacturing where the control group (pixels on the other side of the border) are affected by the land regulation of the treatment group by the potential for people, firms, and capital to relocate across the border.

We document three striking facts. First, we show that up until about 2005, the level and rate of deforestation was dramatically higher on the Brazilian side of the border than in its neighbors. When our data starts in 2000, Brazilian lands were about 30 percent more likely to be have been deforested than similar lands located just a few kilometers away in neighboring countries. And from 2001 to 2005, the annual deforestation rate was more than three times higher on the Brazilian side of the border than in neighboring countries.

Second, we show that the discontinuity in deforestation rates disappears precipitously in 2006 - just as Brazil was implementing substantially tougher national policies targeting illegal deforestation. In November 2004 Brazil launched the Action Plan for the Prevention and Control of Deforestation in the Legal Amazon (PPCDAm) which strengthened the legal penalties associated with illegal deforestation, particularly on unclaimed and private land outside protected areas (Nepstad et al., 2009). PPCDAm was bolstered in 2006 by the Law on Public Forest Management, and by the Center for Environmental Monitoring becoming fully operational, which together enabled the Brazilian state to couple satellitebased detection of deforestation with police and army enforcement operations targeted at areas where illegal deforestation had been detected (MMA, 2008).

\footnotetext{
${ }^{1}$ In fact, in one famous incident, President-elect Cardoso of Brazil went hiking near the border in 1994, and accidentally ended up in Bolivia - and was there for over an hour before anyone realized he was in the wrong country (Cardoso and Winter, 2007, pp. 218-219).

${ }^{2}$ While borders have been shown to be associated with policy outcomes in developed countries (Black, 1999; Holmes, 1998; Turner et al., 2014) where regulations are tightly enforced, the evidence in developing countries is more mixed (Michalopoulos and Papaioannou, 2014; Pinkovskiy, 2017).
} 
Third, we show that de jure land use restrictions on the Brazilian side matter - even at the border. We find that areas designated as protected areas in Brazil have always been less deforested than unprotected lands just on the opposite side of the international border, and this remains the case from 2006 onwards. The Brazilian state was therefore able to enforce environmental regulations when there was the will to do so even in these outlying areas. Instead, reductions in deforestation following the mid-2000s policy changes in Brazil were most pronounced on unclaimed and private lands outside protected areas precisely the types of lands where the increase in enforcement by the Brazilian state was most pronounced (Appendix B.2).

Combined, these results - the sharp discontinuity in deforestation levels and rates at the border, the dramatic change in deforestation at the border when then national government cracks down, and the fact that protected areas in Brazil were always less likely to be deforested than corresponding lands just across the national border - demonstrate the remarkable reach of the Brazilian state. They suggest that the rapid deforestation in the Brazilian Amazon was a consequence of lax enforcement of laws prior to the mid-2000s, and conversely, that the precipitous decline in deforestation seen since the mid-2000s is the consequence of better monitoring and tighter enforcement.

Our results help to understand why the Brazilian Amazon is the only major area of tropical forest that has experienced falling rates of deforestation since the mid-2000s (Figure 1). Brazil (which contains $65 \%$ of the Amazon rainforest) moves from having almost the highest rate of deforestation in 2001 to having the lowest rate in 2014, with the trend reversal occurring in the mid-2000s (see, e.g., Nepstad et al., 2009; Nolte et al., 2013; Godar et al., 2014) In strict contrast Indonesia, the Democratic Republic of Congo and the non-Brazilian Amazon (which contain the bulk of the remaining tropical forest) experience rising deforestation rates across the 2001-2014 period. Identifying the role of Brazilian government policies in causing this decline in deforestation is challenging as these policies were applied throughout the country. ${ }^{3}$ By zooming in on the national border, where Brazil's policy reach ends, we can precisely identify the limits and impacts of being in Brazil and under the Brazilian policy regime. ${ }^{4}$ The methods employed here therefore may be usefully employed by governments concerned with wilderness conservation in other contexts.

The remainder of this paper is organized as follows. In Section 2, we sketch a brief

\footnotetext{
${ }^{3}$ Several papers use variation across Brazilian municipalities for identification. Assunção et al. (2013a) compare areas with more or less cloud cover to argue that satellite-based enforcement contributed to reductions in deforestation, Assunção et al. (2015) compare municipalities with greater or lower "tightness of land constraints" for farmers and Godar et al. (2014) shows that the decline in deforestation is larger in census tracts dominated by large landholders.

${ }^{4} \mathrm{~A}$ related literature studies how regulation and infrastructure affect deforestation (e.g., Adman, 2014; Souza-Rodrigues, 2015; Anderson et al., 2016; Asher et al., 2017) and violence in the Amazon (e.g., Chimeli and Soares, 2017).
} 
model to clarify our identifying assumptions. Section 3 sets our empirical specification and discusses our data. We present results in Section 4. Section 5 concludes.

\section{Theoretical framework: what do we learn from looking at borders?}

\subsection{Model setup}

We build on Turner et al. (2014) and consider a static model of heterogeneous plots of land (pixels) over a line. Each pixel $x \in[-1,1]$ is a parcel of land of equal size covered with native vegetation: $x$ is our index. There is a unit mass of people uniformly spread over the area. The person occupying pixel $x$ chooses whether to preserve the land, or whether to deforest it and produce using land as an input. The value the person derives from preserving the land in each pixel is zero. If a pixel $x$ is put to productive use, the individual chooses how much capital, a mobile factor of production, to use in production.

Pixels are heterogeneous in their productivity. The gross production using capital $k_{x} \geq 0$ in pixel $x$ is $A\left(x, k_{x}\right)$. We assume that $A\left(x, k_{x}\right)$ is continuous everywhere w.r.t $x$ (including at $x=0$ ) and that capital has diminishing returns: $\partial A / \partial k_{x} \geq 0$ and $\partial^{2} A / \partial k_{x}^{2} \leq$ 0 .

Suppose that land is spread across two countries, $L$ and $R$, with $x<0$ belonging to country $L$ and $x \geq 0$ belonging to $R$. Each country imposes different land use regulations. The pixel productivity net of regulation is given by $f\left(x, k_{x}\right)=A\left(x, k_{x}\right) V(x)$, in which:

$$
V(x)= \begin{cases}v_{L} & , \text { if } x<0 \\ v_{R} & , \text { if } x \geq 0\end{cases}
$$

where $v_{L}, v_{R} \in[0,1]$.

For each pixel, the individual chooses whether or not to use the land and how much capital to use. If producing, she chooses $k_{x}^{*}$ to maximize the private returns from using the land, $\Pi\left(x, k_{x}\right)=A\left(x, k_{x}\right) V(x)-r k_{x}$, where $r$ is the price of capital. Implicitly, we assume an elastic global market for output, with price normalized to 1 . The optimal capital use in pixel $x$ conditional on producing is

$$
k_{x}^{*}=\arg \max _{k_{x} \geq 0} \Pi\left(x, k_{x}\right) .
$$

If $\Pi\left(x, k_{x}^{*}\right)<0$, pixel $x$ is preserved and no capital is used.

Imagine the researcher observes productivity, $f\left(x, k_{x}\right)$, for each pixel and runs a spatial regression discontinuity at the border. Comparing the log productivity of pixels on both 
sides of the border and sufficiently close to $x=0$, we have

$$
\lim _{x \rightarrow 0^{+}} \ln f\left(x, k_{x}^{*}\right)-\lim _{x \rightarrow 0^{-}} \ln f\left(x, k_{x}^{*}\right)=\underbrace{\lim _{x \rightarrow 0^{+}} \ln A\left(x, k_{x}^{*}\right)-\lim _{x \rightarrow 0^{-}} \ln A\left(x, k_{x}^{*}\right)}_{\Phi}+\underbrace{\ln v_{R}-\ln v_{L}}_{\rho}
$$

where $\rho$ is the (local) difference of the direct cost of land regulation on productivity and $\Phi$ is the combination of differences in pixel productivity and optimal capital use on each side of the border. ${ }^{5}$

The key point is that $\Phi$ will not necessarily be equal to 0 - even though $\lim _{x \rightarrow 0^{+}} \ln A(x, k)=$ $\lim _{x \rightarrow 0^{-}} \ln A(x, k)$ for any particular value of capital $k$, the optimal capital choice $k^{*}$ may differ on both sides on the border, and if $k_{L}^{*} \neq k_{R}^{*}$ then we cannot assume $\Phi=0$. The next subsections discuss the interpretation of equation (3), and in particular, we show that what we recover from (3) hinges on the elasticity of capital supply around the border.

\section{$2.2 \quad$ Interpretation with elastic capital supply}

Assume that the capital market is locally competitive and capital is supplied elastically at constant price $r$. This implies that capital investment is independent across pixels. In this setting, under the standard assumption that $A(x,$.$) is continuous in x$ (e.g., as in Holmes, 1998; Turner et al., 2014), a spatial regression discontinuity design as in (3) identifies the combination of the direct costs of land regulation, $\rho$, and the indirect costs of the land regulation on productivity, $\Phi$, as regulation in $x$ changes the optimal capital investment in that pixel. This is still the effect of the land regulation, but one that incorporates an endogenous capital response.

To clarify this intuition, suppose $A\left(x, k_{x}\right)=a(x) k_{x}^{\alpha}$, where $a(x)>0$ is the pixel productivity and $\alpha \in[0,1)$. By continuity of $a(x)$, we can write $\Phi=\alpha\left[\lim _{x \rightarrow 0^{+}} \ln k_{x}^{*}-\lim _{x \rightarrow 0^{-}} \ln k_{x}^{*}\right]$. This term will be equal to zero only if the capital share in the production function is zero $(\alpha=0)$ or $\lim _{x \rightarrow 0^{+}} k_{x}^{*}=\lim _{x \rightarrow 0^{-}} k_{x}^{*}$. From the first order condition of the capital investment problem (2):

$$
k_{x}^{*}=\left(\frac{r}{\alpha a(x) V(x)}\right)^{\frac{1}{\alpha-1}}
$$

Since regulation, $V(x)$, is discontinuous at the border, we have that $\lim _{x \rightarrow 0^{+}} k_{x}^{*} \neq \lim _{x \rightarrow 0^{-}} k_{x}^{*}$ in all interior solutions of optimal capital investment.

This suggests when the capital share $(\alpha)$ is equal to 0 , the regression discontinuity in (3) directly identifies the policy parameter $\rho$. When the capital share is non-zero, $\Phi$

\footnotetext{
${ }^{5}$ Whilst equation (3) is interpreted in terms of productivity, our empirical specification below employs a discrete variable for being deforested which is a transformation of equation (3) where, for each person, they deforest their land if $\Pi\left(x, k_{x}^{*}\right)>0$.
} 
would be zero only when there is no interior solution on optimal capital use on both sides of the border. ${ }^{6}$ Otherwise, the regression discontinuity in (3) identifies the total direct and the indirect effect of regulation on productivity, $\Phi+\rho$.

Both parameters are of interest, but it is worth understanding when they diverge. In settings where the capital share $\alpha$ is large (e.g. when land is used for capital-intensive manufacturing), small differences in regulation $\rho$ may lead to large indirect effects $(\Phi)$ of land regulation on land productivity. In contrast, when the capital share is low, as is the case with logging and cattle ranching, estimates of the border regression discontinuity will approximate the direct effect of land regulation $\rho$.

\subsection{Inelastic but locally mobile capital supply}

Imagine now that capital is inelastically supplied, but is locally mobile in an area $(-\bar{x}, \bar{x})$ around the border. Let $r\left(K_{L}(r)+K_{R}(r)\right)$ be the inverse supply function, where $r^{\prime}>0$, and $K_{L}(r)$ and $K_{R}(r)$ are the total quantity of capital used in pixels $x \in(-\bar{x}, 0)$ and $x \in(0, \bar{x})$, respectively. From (4), we have

$$
\begin{aligned}
& K_{L}(r)=\int_{-\bar{x}}^{0} k_{x^{\prime}}^{*}(r) d x^{\prime}=\left(\frac{r}{\alpha v_{L}}\right)^{\frac{1}{\alpha-1}} \int_{-\bar{x}}^{0} a\left(x^{\prime}\right)^{-\frac{1}{\alpha-1}} d x^{\prime} \\
& K_{R}(r)=\int_{0}^{\bar{x}} k_{x^{\prime}}^{*}(r) d x^{\prime}=\left(\frac{r}{\alpha v_{R}}\right)^{\frac{1}{\alpha-1}} \int_{0}^{\bar{x}} a\left(x^{\prime}\right)^{-\frac{1}{\alpha-1}} d x^{\prime} .
\end{aligned}
$$

The equilibrium capital price $r^{*}$ is set by substituting the inverse supply curve and solving for $K_{L}^{*}$ and $K_{R}^{*}$.

The key point here is that the local capital price $r^{*}$ is a function of land regulation on both sides of the border. In other words, the optimal capital investment in pixels close to the border in country $L, k_{x}^{*} \forall x \in(-\bar{x}, 0)$, is affected by land regulation in country $R$ , and vice versa. Thus, when factor markets are locally inelastic but mobile across the border, the regression discontinuity design from $((3))$ does not identify either the net $(\rho)$ or gross $(\Phi+\rho)$ effect of land regulation, because the control group (pixels on the other side of the border) are affected by the land regulation of the treatment group via prices and factor allocation. For example, in the study by Holmes (1998) of state policies and manufacturing output, one might be concerned that a given factory might locate in either state $L$ or state $R$, in which case there may be crowd-out of the sort considered here.

\subsection{Forestry versus other sectors}

The above discussion suggests that one of two conditions are necessary for the RD to be interpretable: either the supply of the mobile factor is completely elastic locally (i.e.

\footnotetext{
${ }^{6}$ That is, $\alpha \geq 1$ and $\lim _{x \rightarrow 0^{+}} k_{x}^{*}=\lim _{x \rightarrow 0^{-}} k_{x}^{*}=0$.
} 
$r^{\prime}=0$ ), or the share of the mobile factor is small (i.e. $\alpha \approx 0$ ).

In the forestry case we consider here, it seems that both these conditions are likely to hold. Most of the land deforested in the Amazon hinterlands is driven by illegal logging and cattle ranching, activities with very low capital investment. ${ }^{7}$ Most importantly, the key factor of production (land) is completely fixed in space, so concerns about cross-border reallocations of the type discussed in Section (2.3) are unlikely to be first-order. Thus, in our case - deforestation - our empirical strategy identifies $\Phi+\rho$ - the net impact of the policy. Moreover, since $\Phi$ is likely small in our case, the net impact $\Phi+\rho$ we identify is likely quite close to the direct impact $\rho$.

\section{Empirical methods and data}

\subsection{Empirical specification}

Our empirical analysis takes place at the $120 \mathrm{~m}$ pixel level. Our running variable is distance to the border. Positive distances represent pixels in the Brazilian Amazon, while negative distances represent pixels in the Amazon outside Brazil.

Our main estimating equation is

$$
Y_{i}=\alpha+\gamma \text { Brazil }_{i}+f\left(\text { DistBorder }_{i}\right)+\delta X_{i}+\varepsilon_{i}
$$

where $Y_{i}$ is the outcome of interest (forest cover in 2000 or forest loss in a given year) in pixel $i$. Brazil $i_{i}$ is a dummy equal to one if pixel $i$ is in Brazil. $f\left(\right.$ DistBorder $\left._{i}\right)=$ Brazil $_{i} * f^{\text {Brazil }}\left(\right.$ DistBorder $\left._{i}\right)+\left(1-\right.$ Brazil $\left._{i}\right) * f^{\text {OutsideBrazil }}\left(\right.$ DistBorder $\left._{i}\right)$ is a polynomial of distance from the border, separately on each side of the border. Following Gelman and Imbens (2014), we use separate linear polynomials $f$ on each side of the border for our preferred specification, and use separate quadratic polynomials as robustness. $X_{i}$ is a vector of controls explained below. We cluster standard errors in blocks of size $50 \mathrm{~km}$ by $50 \mathrm{~km}$ to allow for geographical spatial error correlation. ${ }^{8}$

The coefficient of interest is $\gamma$, which measures the difference in the share of a pixel that is forested in 2000, or deforested in a given year after 2000, on the Brazilian side of the border compared to the other side. We estimate equation (5) by OLS in our main specifications. When we perform exercises to assess if there is heterogeneity in institutional effects across different segments of the border and land types within Brazil, we estimate

\footnotetext{
${ }^{7}$ For cattle ranching, which represents $73 \%$ of the productive land use in Amazonian states of Brazil, the 2006 Census of Agriculture records the average value of tractors and machines employed as $\$ 29$ per hectare; for agriculture, it is $\$ 71$ per hectare. Even logging, which requires some machinery to cut and process wood, does not invest capital in the land as all equipment is carried to the next forested plot.

${ }^{8}$ Conley (1999) would be an alternative but is computationally challenging due to the extremely large number of observations.
} 
equation (5) using a Poisson model. ${ }^{9}$ We do this because there are substantial differences in baseline magnitudes of deforestation across the Amazon across land types, and Poisson estimates remain interpretable as percent changes across land types.

Our identifying assumption is that other factors that might affect deforestation change smoothly across national borders. If this assumption is valid, by controlling for a polynomial in distance from the border, we remove additional sources of biases and allow for causal inference. The idea that the borders are largely arbitrary is consistent with the historical evidence - they were largely set by the 1750 Treaty of Madrid (see Appendix B.2.3) when many of these areas deep in the jungle were largely unexplored and appeared as blank spaces labeled "unknown country" in maps from that time (Furtado, 2012).

To explore this assumption in the data, we check for discontinuities at the border on four factors that may influence deforestation: slope, distance to water, distance to urban areas, and distance to roads. Appendix Table A2 shows the estimates of $\gamma$ which represent the discontinuous change in the level of these variables at the Brazilian border, for various subsets of the border and bandwidths. Overall, columns 1, 4, 7, and 10 show that that these factors are smoothly distributed around the Brazilian border (the remaining columns are for robustness subsamples we discuss in more detail in Section 4.1). Nonetheless, in our main specification we estimate (5) controlling for natural covariates: land slope and distance from water. We present results both without any controls and including additional controls for distance to infrastructure in the robustness tables.

We report results using bandwidths around the border ranging from $5 \mathrm{~km}$ to 100 $\mathrm{km}$. Since we have different dependent variables in different columns, we do not have a single theory-driven optimal bandwidth. We calculate the optimal bandwidth for each dependent variable as Imbens and Kalyanaraman (2012). The optimal bandwidth of forest cover in 2000 is $5 \mathrm{~km}$ from the border, but varies for our annual deforestation variables. To ease comparability across equations, our preferred bandwidth is the average of the optimal bandwidths calculated across all variables, which is $17 \mathrm{~km}$ from the border. In our preferred specification using all $120 \mathrm{~m}$ pixels within $17 \mathrm{~km}$ of the border, we have 301 clusters and 20,537,712 observations each year.

\subsection{Data}

Hansen et al. (2013) worked with Google Earth Engine to detect deforestation using Landsat 7 data, resulting in a map of global forest cover in 2000 and consistent longitudinal annual forest measures from 2001 to 2014, at a spatial resolution of 30 meters across the whole earth. The forest cover map is constructed for 2000 exactly because Landsat 7 was launched in the previous year, so Hansen uses it as the base cover on which he constructs

\footnotetext{
${ }^{9}$ Since each $120 \mathrm{~m}$ pixel is comprised of $1630 \mathrm{~m}$ pixels, our dependent variable is effectively a count variable with range $[0,16]$.
} 
annual forest loss. Importantly, since this dataset is worldwide and does not use any national data as inputs, we can examine deforestation rates on both sides of the border using an exactly comparable metric. We aggregate pixels to create a resolution of $120 \times 120$ meters. Annual forest loss is defined as the share of $30 \mathrm{~m}$ Landsat pixels within our $120 \mathrm{~m}$ pixels deforested within one year. Forest cover in 2000 is the average tree cover canopy of the Landsat pixels. Summary statistics are shown in Appendix Table A1.

We limit our analysis to the Amazon area as defined by RAISG (La Red Amazónica de Información Socioambiental Georreferenciada), taking into account the biome and the legal Amazon limits as defined by the various countries in the region. On net, we have more than 277 million observations in the Amazon each year.

Figure 2 shows an example of the data, displaying forest cover as of 2000. Panel (a) shows the entire Amazon, and Panel (b) zooms in on one particular border segment, which consists largely of straight lines. The substantially higher deforestation on the Brazilian (right-hand) side of the border is visually apparent.

We supplement this deforestation data with a variety of other data sources. Hydrology data from 2000 was extracted from Google Earth Engine. Remaining data including administrative boundaries, protected areas, elevation, slope, waterways,roads and urban areas were extracted from OpenStreetMap's API.

\section{Results}

\subsection{Deforestation as of 2000}

We begin by examining the level of forest cover in 2000, the year our data begins. Figure 3 shows the percentage of forest cover in 2000 averaged by eighty equal-sized bins of distances from the Brazilian border, up to one hundred kilometers from each side of the border. The sharp discontinuity in deforestation is visually apparent: forest cover drops sharply exactly at the national border.

Our regression estimates using equation (5) indicate that this discontinuous change in forest cover at the border is sizable and statistically significant. Using a $17 \mathrm{~km}$ bandwidth, forest cover in the Brazilian Amazon was around 3.3 percentage points smaller than in its neighboring countries (p-value $<0.01$; see Appendix Table A3). ${ }^{10}$ Since $89 \%$ of the land outside of Brazil was forested in 2000, this implies that deforestation prior to 2000 was 30 percent higher just inside the Brazilian border than just on the other side.

\footnotetext{
${ }^{10}$ Results vary from 1.2 percentage points to 5.6 percentage points, depending on bandwidth, which we vary from $5 \mathrm{~km}$ to $100 \mathrm{~km}$. Estimates remain statistically significant at the $5 \%$ level in all specifications.
} 


\subsection{Annual Forest Loss}

We next plot annual deforestation rates on both sides of the border annually between 2001 and 2014 in Figure 4. The figures show a dramatic difference in deforestation rates in 20012005 that comes to an abrupt halt in 2006. Between 2006 and 2012, deforestation activity is smoothly spread on both sides of the Brazilian border. Note also that the change in 2006 comes from decreased deforestation in Brazil, rather than increased deforestation on the other side of the border.

We estimate RD models separately for each year. Figure 5a plots the RD coefficient $-\gamma$ in equation (5) - from each year, along with $95 \%$ confidence intervals, using OLS regressions and a $17 \mathrm{~km}$ bandwidth. ${ }^{11}$ We estimate annual deforestation rates of about 0.2 percentage points higher per year on the Brazilian side of the border through 2005. Since deforestation on the other side of the border ranged from 0.05 to 0.8 percent in the other Amazonian countries, the estimates imply deforestation rates in Brazil were 3-4 times faster than on the other side of the border.

The dramatic changes we observe at the border correspond to a period of policy strengthening in Brazil (Appendix B.1). ${ }^{12}$ Although the PPCDAm plan was released in 2004, its actions were implemented gradually: most notably with the Law on Public Forest Management and Center for Environmental Monitoring becoming fully operational in 2006. This allowed the satellite-based deforestation detection system (DETER) to become a key tool for targeting law enforcement activities in the Brazilian Amazon including sending in federal police and troops to arrest illegal loggers and confiscate their machinery. (MMA, 2008). Consonant with this, Figure 4 shows that in 2006 deforestation on the Brazilian side of the border collapses and the discontinuity at the border is eliminated. Taken together these results to point to an important role for Brazilian policy in determining deforestation rates at the border. ${ }^{13}$

These results are robust to a series of alternative specifications and samples. Our baseline RD specifications use OLS and control for slope and distance to water, use linear polynomials, and are estimated using the entire Brazilian border. Appendix Table A4 shows that the results are qualitatively similar if we: a) do not include the slope and distance to water controls; b) add additional 'infrastructure' controls; c) estimate using Poisson models; d) use quadratic polynomials; and e) exclude a $220 \mathrm{~km}$ buffer around the

\footnotetext{
${ }^{11}$ Estimates with alternate bandwidths are shown in Appendix Table A3 .

${ }^{12}$ These followed the appointment in 2003 of Marina Silva as Minister of Environment who was from a poor family in the Amazon region and had a strong predilection towards conserving the rainforest.

${ }^{13} \mathrm{An}$ alternative explanation for the precipitous change we observe in 2006 is a differential change in output prices. To investigate this, we obtained national domestic farmgate prices for soybeans, the main crop in these regions, for both Brazil and Bolivia (the border country closest to the Brazilian agricultural frontier), from the FAO (consistent data on cattle prices are not available). As shown in Appendix Figure A3, farmgate prices move almost directly in parallel in both countries through 2011, and there is no differential break in prices around 2006.
} 
peak of Mount Roraima, a small section of the northern border with Venezuela, which is coincident with a mountain ridge and the only part of the border where there are differences in slope at the border.

Perhaps most importantly, we also estimate results restricting the sample to areas around artificial borders, as in Alesina et al. (2011) - i.e. borders arbitrarily drawn by former colonizers which appear as straight lines on a map (Appendix B.2.3). ${ }^{14}$ For these borders, there is no geographic feature at the border. Nevertheless, we find even larger effects, as shown in Figure A1 (see Appendix Table A4 Panel C).

\subsection{Heterogeneity by land classification within Brazil}

We next probe heterogeneity in effects based on the land use classification of different areas within Brazil. Since 1998, destroying or harming native vegetation in Protected Areas (PAs) was a felony subject to potentially harsh legal procedures and punishments - including possible jail time. This category of land thus faced the highest level of de jure sanction throughout the 2000-2014 period. In contrast, PPCDAm made several changes that increased enforcement outside PAs.

Most notably, until 2005, deforesting untitled, or unclaimed land, outside PAs was just an infraction, punishable at most with fines and individuals caught harming native vegetation or extracting resources in these lands could not even have their equipment seized. PPCDAm made deforestation of unclaimed land a felony punishable with jail time, as in PAs, and legislated that equipment (i.e. trucks and chainsaws) of violators could be seized and confiscated.

Similarly until 2005, private properties outside PAs were required to set aside at least $35 \%$ of their area as native vegetation - i.e., it was illegal to deforest more than $65 \%$ of the private property area. Non-compliance with this threshold, however, was just an infraction. Starting in 2005, PPCDAm both increased the required set aside area of private properties from $35 \%$ to $80 \%{ }^{15}$ and conditioned access to agricultural credit lines from public banks on environmental compliance (Assunção et al., 2013b).

To explore whether differences in de jure enforcement regimes translated into differences in de facto deforestation at the border, we re-estimate equation (5) separately for each of these three classes of land. Figure $5 \mathrm{~b}$ presents the results, where every point is an estimated RD coefficient (i.e. $\gamma$ from (5)) from a separate Poisson regression. As above, these estimates all use a bandwidth of $17 \mathrm{~km}$.

We see that when the national border abuts PAs we observe less deforestation on the Brazilian side consistent with these areas enjoying greater de jure protection throughout

\footnotetext{
${ }^{14}$ We map the segments of artificial border in Figure A4b in the appendix.

${ }^{15}$ Pre-2005 infringements were not prosecuted but landowners were liable for any deforestation above the $20 \%$ requirement from 2005 onward.
} 
our whole period. In strict contrast, for unclaimed lands we observe more deforestation on the Brazilian side up until 2005 but this discontinuity is eliminated from 2006 when PPCDAm comes into full force. For private lands, while there is a dramatic fall in the difference in deforestation rates in 2006, it is not eliminated entirely, consistent with the fact that some deforestation was still allowed in these areas. These results confirm that - even in these remote areas very close to the international border - differences in deforestation map to changes in land use regulations within Brazil.

\section{Conclusion}

By using fine grained satellite data we are able to test whether Brazilian conservation policies had any bite at the national border. This is an interesting exercise as there has been considerable skepticism regarding the ability of the state to exercise control over the hinterland. In effect, the ability of the state to conserve ecosystems may fall as locations become remote, which opens up opportunities for those who want to illegally extract resources. Given that rapid environmental degradation in developing countries is being driven by illegal extraction it is important to empirically assess whether or not the state has the power to conserve natural resources in these remote locations.

This is the contribution of this paper. We observe sharp discontinuities in forest loss at the border and a diminution in these as Brazil implemented policies to detect and and penalize illegal logging. Our results therefore demonstrate the power of the state to determine whether remote wilderness ecosystems are conserved or exploited. Moreover, the pattern of diminution within Brazil, where post-2005 deforestation rates fall mainly in non-protected areas, again points to the influence of national policies on conservation.

This finding has implications not only for Brazil but also for the rest of the world. The future path of the earth's climate will, to some significant extent, be determined by whether vast wilderness ecosystems like the Amazon can be kept intact. The fact that Brazil moves from having almost the highest rate of deforestation in 2001 to having the lowest rate in 2014 is testament to how conservation policy can be turned around. Part of this turnaround was achieved by the Brazilian state coupling better monitoring (through use of satellite data) with more stringent enforcement (through the use of federal police).

The success of wilderness conservation, therefore, ultimately depends on the policy choices of national governments. Information on illegal logging, for example, is regularly available to any government at a 30 meter resolution (Hansen et al., 2013). Whether or not governments act on this information is another matter and depends largely on the political willingness to do so. Nevertheless, the remarkable reversal we document in Brazil suggests that it is possible to reduce the gap between de jure and de facto conservation policy, even in wilderness areas in developing countries. 


\section{References}

Adman, R. (2014). Reelection incentives, blacklisting and deforestation in the brazilian amazon. Technical report, .

Alesina, A., Easterly, W., and Matuszeski, J. (2011). Artificial states. Journal of the European Economic Association, 9(2):246-277.

Allan, J. R., Venter, O., and Watson, J. E. (2017). Temporally inter-comparable maps of terrestrial wilderness and the last of the wild. Scientific data, 4:170187.

Anderson, L. O., De Martino, S., Harding, T., Kuralbayeva, K., Lima, A., et al. (2016). The effects of land use regulation on deforestation: Evidence from the brazilian amazon. Technical report, Oxford Centre for the Analysis of Resource Rich Economies, University of Oxford.

Asher, S., Garg, T., and Novosad, P. (2017). The ecological footprint of transportation infrastructure.

Assunção, J., Gandour, C., and Rocha, R. (2013a). Deterring deforestation in the brazilian amazon: Environmental monitoring and law enforcement. Technical report, Climate Policy Institute.

Assunção, J., Gandour, C., Rocha, R., and Rocha, R. (2013b). Does credit affect deforestation? evidence from a rural credit policy in the brazilian amazon. Technical report, Climate Policy Institute.

Assunção, J., Gandour, C. C., and Rocha, R. (2015). Deforestation slowdown in the legal amazon: prices or policies? Environment and Development Economics, 20(6):697-722.

Black, S. E. (1999). Do better schools matter? parental valuation of elementary education*. The Quarterly Journal of Economics, 114(2):577-599.

Cardoso, F. H. and Winter, B. (2007). The accidental president of Brazil: a memoir. PublicAffairs.

Chimeli, A. B. and Soares, R. R. (2017). The use of violence in illegal markets: Evidence from mahogany trade in the brazilian amazon. American Economic Journal: Applied Economics, 9(4):30-57.

Conley, T. G. (1999). Gmm estimation with cross sectional dependence. Journal of Econometrics, 92:1-45. 
D'Anville, J.-B. B. (1779). Mémoire sur un accoissement considérable de connoissances locales en ce qui intéresse l'amérique méridionale. Robert Bosch Collection, Stuttgart, Germany. n. 539, 11p.

Furtado, J. F. (2012). Oraculos da geografia ilumisnista: Dom Luís da Cunha e JeanBaptiste Bourguignon d'Anville na construção da cartografia do Brasil. Editora UFMG.

Gelman, A. and Imbens, G. (2014). Why high-order polynomials should not be used in regression discontinuity designs. Technical report, National Bureau of Economic Research.

Godar, J., Gardner, T. A., Tizado, E. J., and Pacheco, P. (2014). Actor-specific contributions to the deforestation slowdown in the brazilian amazon. Proceedings of the National Academy of Sciences, 111(43):15591-15596.

Hansen, M. C., Potapov, P. V., Moore, R., Hancher, M., Turubanova, S., Tyukavina, A., Thau, D., Stehman, S., Goetz, S., Loveland, T., et al. (2013). High-resolution global maps of 21st-century forest cover change. Science, 342:850-853.

Herbst, J. (2000). States and Power in Africa: Comparative Lessons in Authority and Control. Princeton University Press.

Holmes, T. J. (1998). The effect of state policies on the location of manufacturing: Evidence from state borders. Journal of Political Economy, 106(4):667-705.

Imbens, G. and Kalyanaraman, K. (2012). Optimal bandwidth choice for the regression discontinuity estimator. The Review of Economic Studies, 79:933-959.

IPBES (2018). Plenary of the Intergovernmental Science-Policy Platform on Biodiversity and Ecosystem Services, 6th Session.

Michalopoulos, S. and Papaioannou, E. (2014). National institutions and subnational development in africa. The Quarterly Journal of Economics, 129(1):151-213.

MMA, M. d. M. A. (2008). Plano de Ação para Prevenção e Controle do Desmatamento na Amazônia Legal (PPCDAm). Documento de Avaliação 2004-2007.

MMA, M. d. M. A. (2013). Plano de Ação para Prevenção e Controle do Desmatamento na Amazônia Legal (PPCDAm) 3a Fase (2012-2015) pelo uso sustentável e conservação da Floresta. Brasília.

Nepstad, D., Soares-Filho, B. S., Merry, F., Lima, A., Moutinho, P., Carter, J., Bowman, M., Cattaneo, A., Rodrigues, H., Schwartzman, S., et al. (2009). The end of deforestation in the brazilian amazon. Science, 326:1350-1351. 
Nolte, C., Agrawal, A., Silvius, K. M., and Soares-Filho, B. S. (2013). Governance regime and location influence avoided deforestation success of protected areas in the brazilian amazon. Proceedings of the National Academy of Sciences, 110(13):4956-4961.

Pfaff, A. S. (1999). What drives deforestation in the brazilian amazon?: evidence from satellite and socioeconomic data. Journal of Environmental Economics and Management, 37:26-43.

Pinkovskiy, M. L. (2017). Growth discontinuities at borders. Journal of Economic Growth, 22(2):145-192.

Souza-Rodrigues, E. (2015). Deforestation in the amazon: A unified framework for estimation and policy analysis. Technical report, University of Toronto.

Turner, M. A., Haughwout, A., and Van Der Klaauw, W. (2014). Land use regulation and welfare. Econometrica, 82(4):1341-1403. 


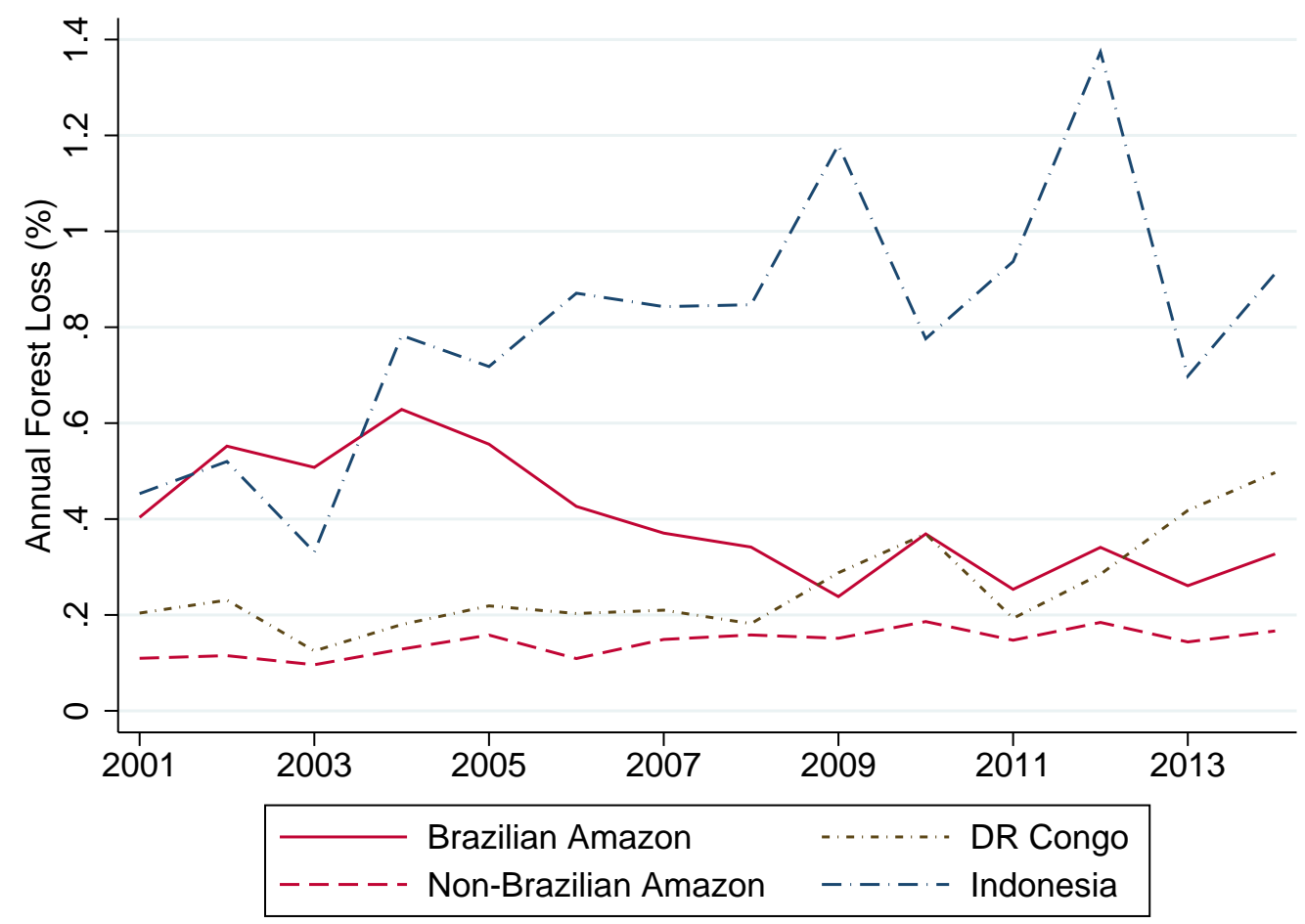

Figure 1: Forest Change in the Amazon, DR Congo and Indonesia, 2001-2014

This figure shows the annual forest loss in the Brazilian and non-Brazilian Amazon, in the Democratic Republic of the Congo and Indonesia, as calculated by the authors using data from (Hansen et al., 2013). Forest loss is measured as the share of forest cover in each country that was lost in each year. 


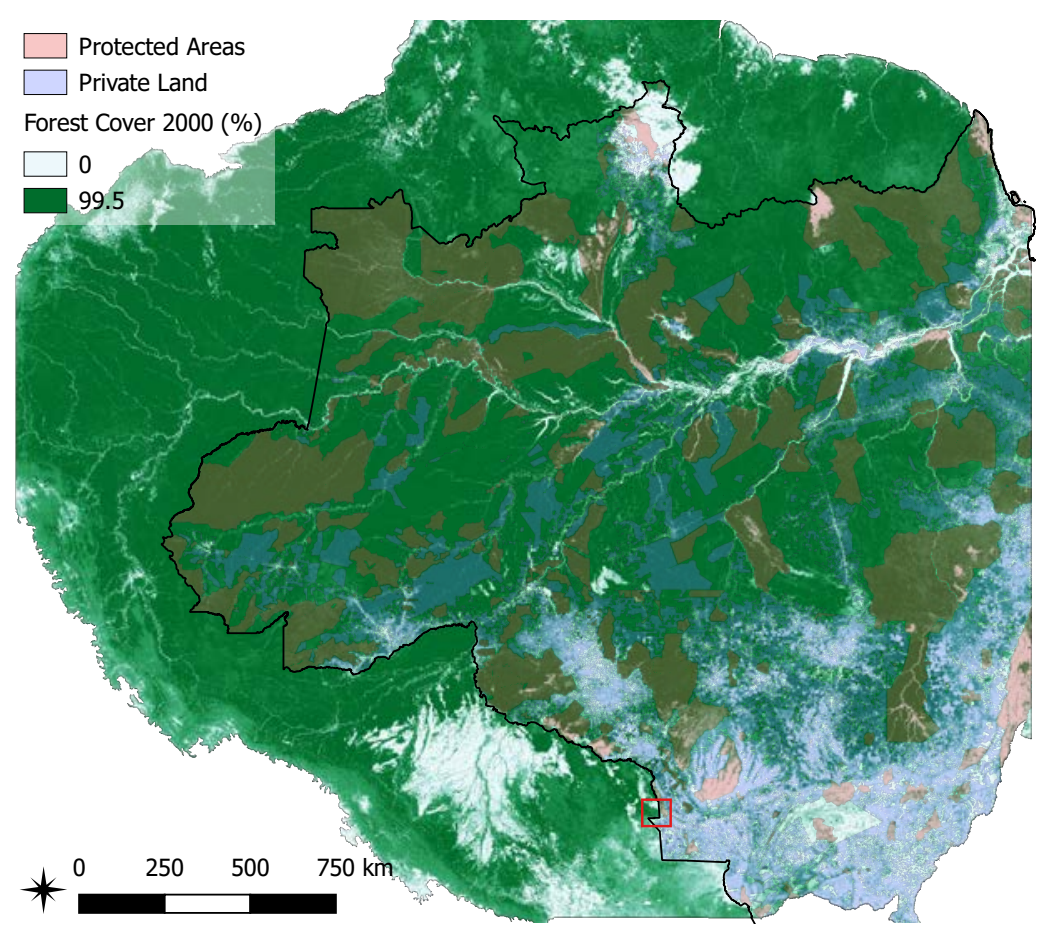

(a) Overview

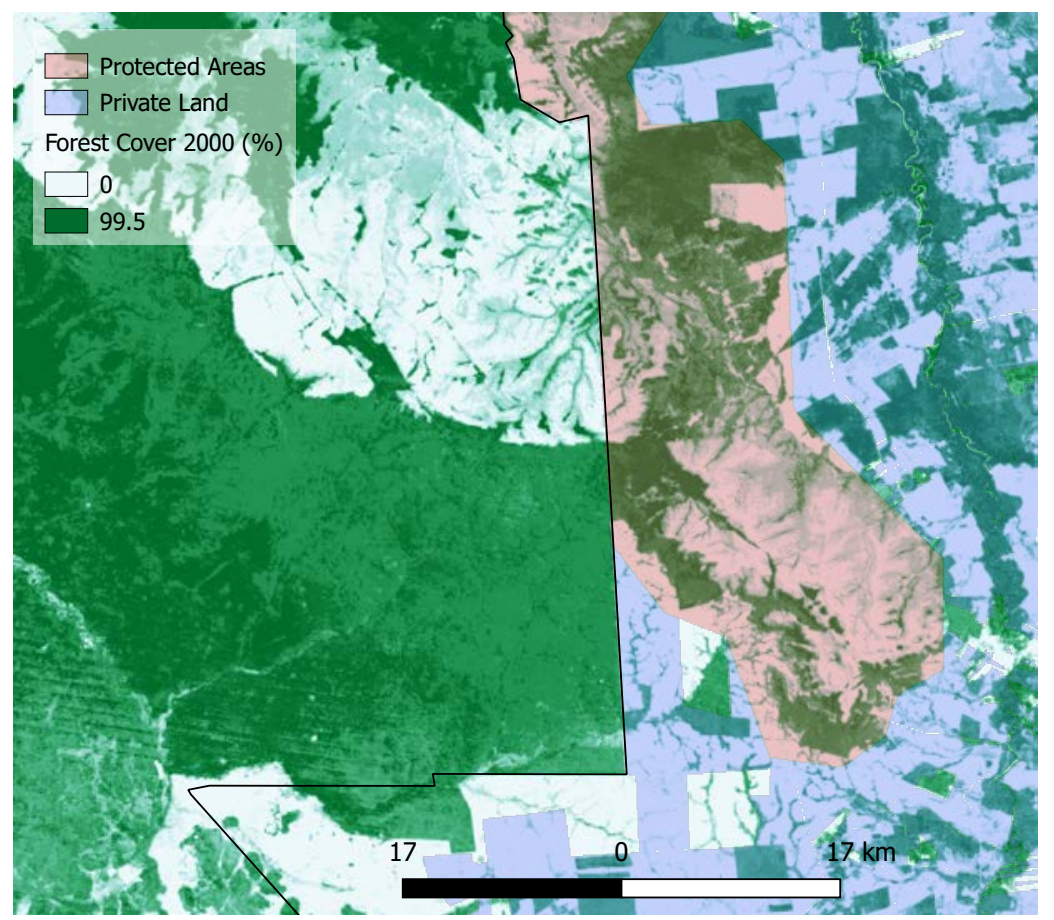

(b) Example of area of border with Bolivia

Figure 2: Satellite Image of a Border Segment (Percentage of Forest Cover in 2000)

This figure shows the percentage of forest cover in 2000 by 120 meter pixels, as calculated by the authors using data from (Hansen et al., 2013). The top panel (a) shows the Amazon, and the bottom panel (b) shows a zoom in a segment of the border between Brazil and the Southern border with Bolivia (marked with a red square in the top panel). The black solid line is the Brazilian border. Forest cover in shades of green (white are deforested pixels). Red shades mark Protected Areas as of 2004. Blue shades mark private non-protected land. 


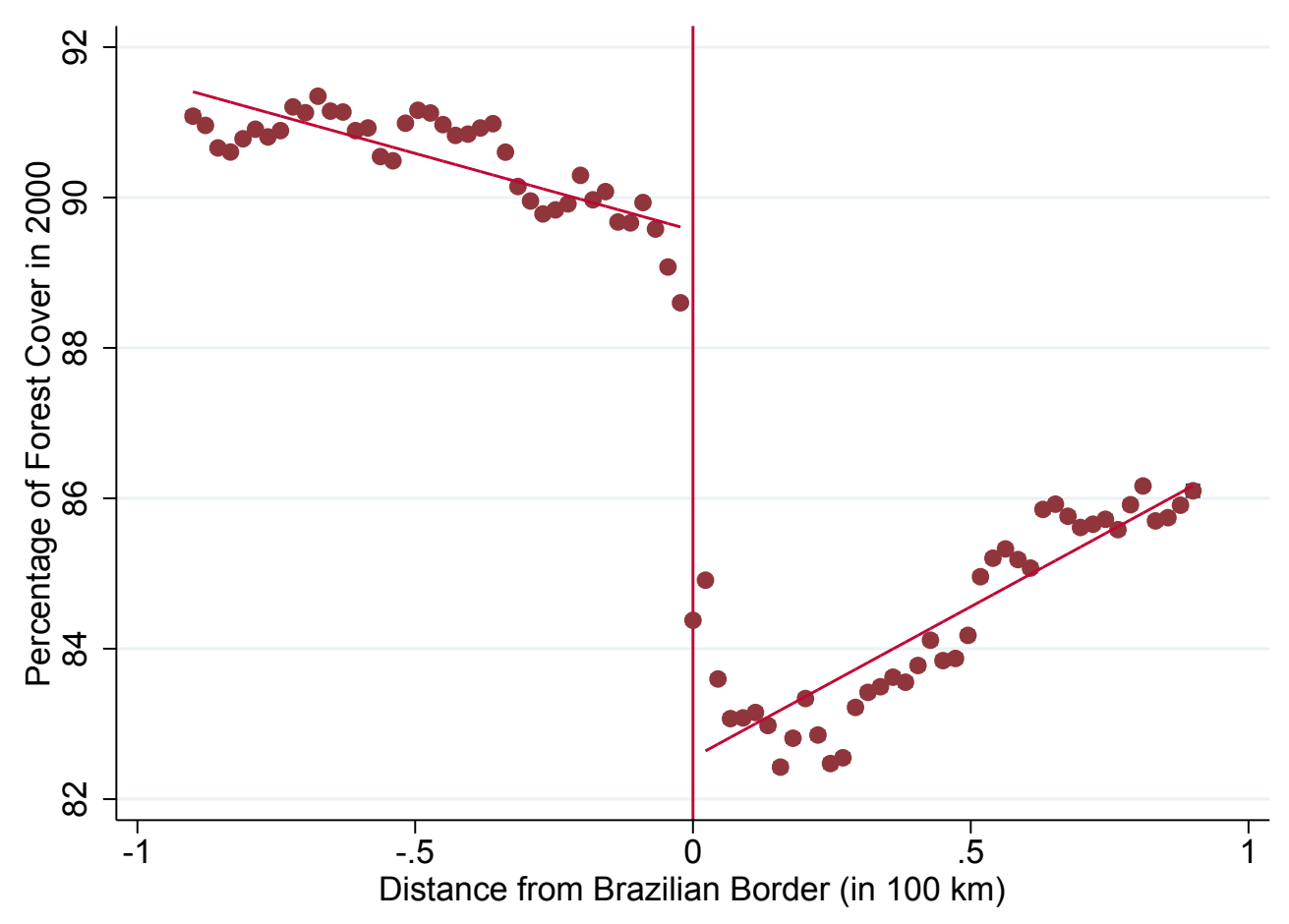

Figure 3: Average Forest Cover in 2000 by Distance from Brazilian Border

This figure shows the average forest cover in 2000 by 80 equal-sized bins of distances from the Brazilian border, up to 100 kilometers away from the border. Positive distance represents Brazilian land, while negative distance represents non-Brazilian land. The vertical bars (not always visible) depict $95 \%$ confidence intervals of the local average within each bin. The red line shows the linear function of distance weighted by the number of observations in each bin. 




Figure 4: Average Annual Forest Loss at the Border by Year - 2001-2014

This figure shows the average annual forest cover lost each year between 2001 and 2014 by 80 equal-sized bins of distances from the Brazilian border. Each figure present pixels more distant from the border, up 100 kilometers away from the border. Positive distance represents Brazilian land, while negative distance represents non-Brazilian land. The vertical bars (not always visible) depict $95 \%$ confidence intervals of the local average within each bin. The red line shows the linear function of distance weighted by the number of observations in each bin. 


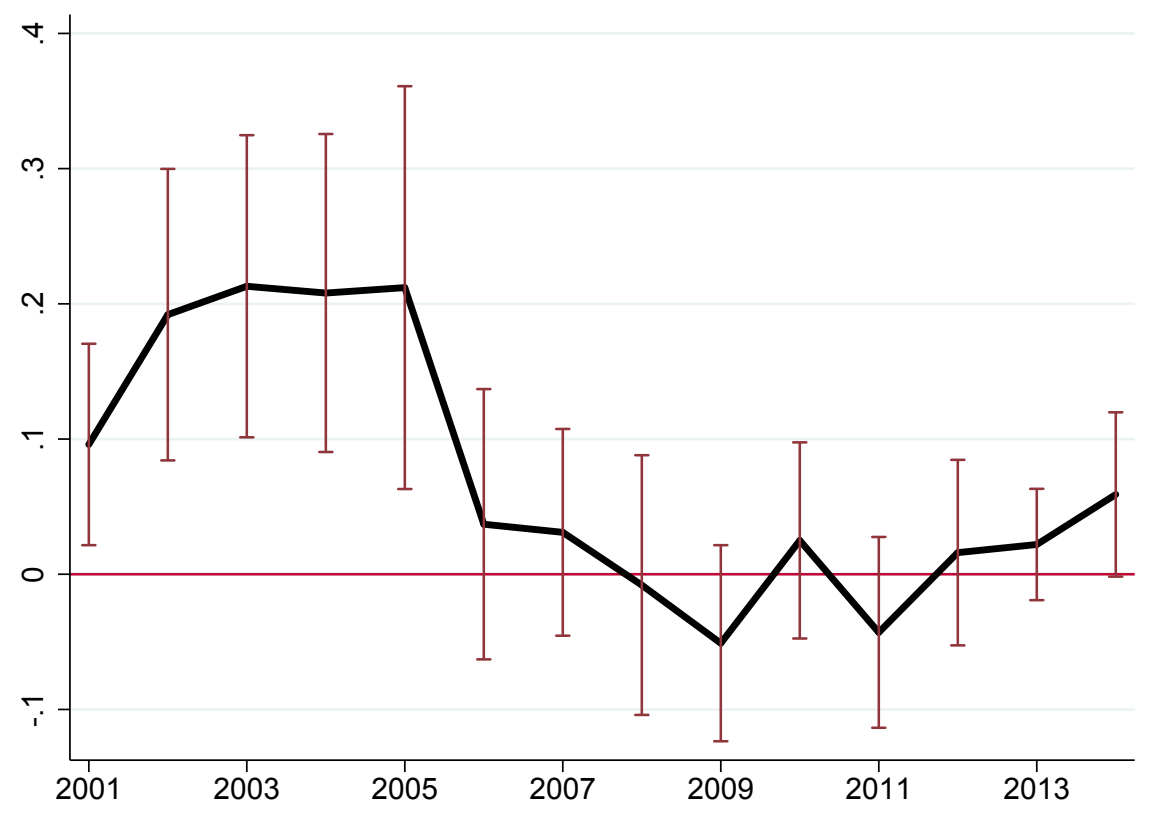

(a) Overall Effects (OLS model)



(b) Heterogeneous Effects by Land Type (Poisson model)

Figure 5: Regression Discontinuity Coefficients by Year

This figure shows the regression discontinuity coefficients of the Brazilian effect, $\gamma$, on the percentage of annual forest loss by year, from equation (5) with linear polynomials and $17 \mathrm{~km}$ bandwidth. The top panel (a) shows the overall effects estimated using the whole Brazilian border trough OLS regressions (presented in Panel A Table A3 in Appendix). The vertical bars represent $95 \%$ confidence intervals. The bottom panel (b) shows the heterogeneous effects by land type estimated using a Poisson model (presented in Table A5 in Appendix). These estimates can be interpreted as a relative increase in the Brazilian side of the border. 